\title{
PROJETOS INOVADORES, CONTEXTOS FUNDAMENTAIS E LACUNAS DE PESQUISA NA PERSPECTIVA DAS CIDADES EDUCADORAS
}

\author{
INNOVATIVE PROJECTS, FUNDAMENTAL CONTEXTS AND RESEARCH GAPS FROM THE \\ PERSPECTIVE OF EDUCATING CITIES
}

\section{PROYECTOS INNOVADORES, CONTEXTOS FUNDAMENTALES Y LAGUNAS DE INVESTIGACIÓN EN LA PERSPECTIVA DE LAS CIUDADES EDUCADORAS}

\author{
Alceli Ribeiro Alves \\ Doutor em Geografia pela Universidade Federal do Paraná (UFPR). Professor e Coordenador de cursos de \\ Pós-Graduação Lato Sensu do Centro Universitário Internacional UNINTER, Curitiba/PR - Brasil. \\ ORCID: http://orcid.org/o00o-0002-2256-2915, e-mail: alceli.a@uninter.com
}

\begin{abstract}
Nelson Pereira Castanheira
Doutor em Engenharia de Produção pela Universidade Federal de Santa Catarina (UFSC). Pró-Reitor de PósGraduação, Pesquisa e Extensão do Centro Universitário Internacional UNINTER, Curitiba/PR - Brasil. ORCID: http://orcid.org/0000-0002-5936-2917, e-mail: nelson.c@uninter.com
\end{abstract}

\begin{abstract}
RESUMO
Pensar a cidade, com a cidade e para a cidade tem se tornado uma tarefa envolvente não apenas para os gestores municipais. Quando a educação é considerada fator fundamental para o desenvolvimento da cidade, surge a cidade como meio para uma formação integral do cidadão, desde a mais tenra idade. É nesse contexto que emerge a Cidade Educadora, uma proposta política e pedagógica transformadora do século XXI. Nesse sentido, o objetivo deste trabalho consiste em analisar os contextos fundamentais nos quais a perspectiva da cidade educadora emergiu e atualmente se desenvolve. Essa análise é importante para compreendermos as atuais iniciativas realizadas sob a bandeira da cidade educadora, outra tarefa que nos propusemos a realizar aqui. A metodologia aplicada consiste em pesquisa bibliográfica e documental. Os resultados obtidos nos revelam que a Cidade Educadora é uma arena rica de debates, inovações e de mobilização das administrações públicas municipais em prol da educação e da gestão participativa. Algumas lacunas de pesquisa também foram identificadas e, por isso, reflexões e questionamentos foram levantados, podendo servir como ponto de partida para pesquisas futuras. Por último, conclui-se que a cidade ocupa papel fundamental no desenvolvimento das pessoas e na formação cidadã, mas para que não se torne um discurso utópico, a Cidade Educadora deve fortalecer o desenvolvimento de projetos que promovam o engajamento das comunidades, instituições, escolas, etc. na construção da cidade que queremos para as próximas décadas, fazendo com que participem ativamente das mudanças que desejam para a educação e para as cidades envolvidas.
\end{abstract}

Palavras-chave: Cidades Educadoras; Cidade; Educação; Educador.

\begin{abstract}
Thinking about the city, with the city, and for the city has become an engaging task not only for city managers. When education is considered a fundamental factor for the city's development, the city arises as a means for a comprehensive education of the citizen, from an early age. In this context, the Educating City emerges, a transformative political and pedagogical proposal of the 21st century. Hence, the objective of this work is to analyse the fundamental contexts in which the perspective of the educating city has emerged and is currently developing. This analysis is essential to understand the current initiatives carried out under the banner of the educating city, another task that we proposed to do here. The applied methodology consists of bibliographic and documentary research. The results obtained reveal that the Educating City is a rich arena for debates, innovations, and mobilization of municipal public administrations in favor of education and participatory management. Some research gaps were also identified, and, therefore, reflections and questions were
\end{abstract}


raised, which can serve as a starting point for future research. Finally, it is concluded that the city plays a fundamental role in the development of people and the formation of citizens. However, so that it does not become a utopian discourse, the Educating City must strengthen the development of projects that promote the engagement of communities, institutions, schools, and so forth, in the construction of the city we want for the following decades, making them actively participate in the changes they want for education and the cities involved.

Keywords: Educating Cities; City; Education; Educator.

\section{RESUMEN}

Pensar la ciudad, con la ciudad y para la ciudad se ha vuelto una tarea absorbente no solo para los gestores municipales. Cuando la educación es considerada como factor fundamental para el desarrollo de la ciudad, esta surge como medio para la formación integral del ciudadano, desde la más tierna edad. Es en ese contexto que emerge la Ciudad Educadora, una propuesta política y pedagógica transformadora del siglo XXI. En ese sentido, el objetivo de este trabajo consiste en analizar los contextos fundamentales en los cuales la perspectiva de ciudad educadora surgió y actualmente se desarrolla. Ese análisis es importante para que comprendamos las iniciativas actuales, realizadas bajo la bandera de la ciudad educadora, otra tarea que nos propusimos realizar acá. La metodología aplicada consiste en investigación bibliográfica y documental. Los resultados obtenidos nos revelan que la Ciudad Educadora es una rica arena de debates, innovaciones y de movilización de las administraciones públicas municipales en favor de la educación y de la gestión participativa. Algunas lagunas de investigación también fueron identificadas y, por ello, reflexiones e interrogantes fueron presentadas, las cuales podrán servir como punto de partida para investigaciones futuras. Por último, se concluye que la ciudad tiene un rol fundamental en el desarrollo de las personas y en la formación ciudadana, sin embargo, para que no se vuelva un discurso utópico, la Ciudad Educadora debe fortalecer el desarrollo de proyectos que fortalezcan el compromiso de las comunidades, instituciones, escuelas, etc., en la construcción de la ciudad que anhelamos para las próximas décadas, haciendo que participen activamente en los cambios que desean para la educación y para las ciudades concernidas.

Palabras-clave: Ciudades Educadoras; Ciudad, Educación; Educador.

\section{INTRODUÇÃO}

Todos os anos, as Nações Unidas publicam o World Urbanization Prospects, um relatório anual tratando das perspectivas de urbanização mundial. Na publicação de 2015, além da revisão dos dados de 2014, o material apresentava as principais descobertas e tendências de urbanização no mundo entre 1950 e 2050.

Conforme a citada publicação, atualmente mais pessoas vivem em áreas urbanas do que em áreas rurais. Em 1950, cerca de 70\% da população mundial vivia em áreas rurais e menos de um terço (30\%) vivia em áreas urbanas. Em 2007, pela primeira vez na história a população urbana global excedeu a população rural.

Em 2014, 54\% da população mundial era urbana. A perspectiva é que, em 2050, cerca de $66 \%$ da população mundial viverá em áreas urbanas e $34 \%$ em áreas rurais. Em vista disto, são inevitáveis os questionamentos: o que isso tem a ver com a cidade educadora? Por que devemos nos preocupar com o fenômeno urbano e a cidade propriamente dita? 
Ora, se a maioria da população mundial vive hoje nas cidades, ou melhor, nas áreas urbanas dessas cidades, e cada vez mais viveremos nesses espaços, logo, é fundamental pensarmos a cidade que queremos, conhecermos e aprendermos com ela, para que nela possamos viver melhor, nos apropriarmos dela e ajudarmos a construí-la e transformá-la.

Para além das questões teóricas e conceituais a serem discutidas neste trabalho em torno da cidade, do crescimento populacional e da urbanização de modo geral, é importante destacarmos também que os aumentos nas taxas de urbanização trazem enormes desafios para a gestão de cidades, haja vista a necessidade de se planejar e administrar a cidade e as demandas de seus cidadãos no curto, médio e longo prazos.

Nesse contexto, diversos eixos de discussão e temas da atualidade são elencados na perspectiva das Cidades Educadoras, tais como a gestão participativa, a demanda por serviços públicos, o meio ambiente, os espaços públicos, a infraestrutura das cidades, a mobilidade urbana, a moradia, o emprego, transportes, saúde, educação, entre outros.

Portanto, pensar a cidade na perspectiva da cidade educadora requer visão holística, multidisciplinar e transversal dos processos que envolvem a cidade e sua evolução ao longo do tempo.

A partir dessas considerações, o objetivo deste trabalho é explorar algumas questões importantes na perspectiva das Cidades Educadoras, a saber: como surgiram? Em quais contextos emergiu e se desenvolve? Considerando quais problemas e desafios? O que são? Que objetivos possuem? Como fazer para que a proposta política e pedagógica da cidade que educa seja implementada de modo que cumpra seu papel fundamental?

Ademais, na literatura há uma variedade de terminologias que podem confundir a compreensão do leitor sobre essa ou aquela perspectiva. Consideremos, por exemplo, a cidade inteligente, a cidade sustentável, a cidade saudável ou a cidade resiliente.

Ou seja, ao mesmo tempo que enfatizamos e tratamos da necessidade de se conhecer a cidade em um primeiro plano (suas diversas escalas, manifestações, seus rótulos, suas estratégias de desenvolvimento, políticas públicas, etc.), nosso olhar neste trabalho é também voltado a essas questões que buscam contribuir para resgatar o contexto histórico, político e socioeconômico de surgimento e formação da cidade educadora.

Por último, sem muita ambição, e reconhecendo os desafios ao longo da caminhada na perspectiva da cidade educadora, buscamos sinalizar a escassez de estudos 
em três eixos temáticos propostos no âmbito dessa perspectiva, quais sejam, a gestão participativa, a intersetorialidade e o direito à cidade. Neste aspecto, em particular, a questão da moradia.

Veremos que existem iniciativas bastante louváveis, mas que há ainda muito espaço para proposição, amadurecimento e execução de projetos que mergulhem profundamente nessas questões, permitindo colocar em prática ações efetivas em nossas cidades, escolas e instituições.

\section{Metodologia}

O presente trabalho é um artigo de desenvolvimento teórico, embasado predominantemente em pesquisa bibliográfica e documental. No que concerne à pesquisa bibliográfica, o trabalho parte de livros, artigos científicos, teses, dissertações, além de outras publicações sobre o tema, tais como jornais, revistas especializadas, periódicos, etc.

A pesquisa documental explora o banco de experiências das Cidades Educadoras, bem como legislações com ampla discussão acerca da produção do espaço e dos direitos humanos fundamentais. Aqui, destacamos a Constituição da República Federativa do Brasil, além de leis específicas, tais como a lei de zoneamento, uso e ocupação do solo.

Quanto às lacunas de pesquisa identificadas na perspectiva das cidades educadoras, ressaltamos que tal afirmação se apoia em consultas e análises do banco de experiências da AICE. Para essa tarefa, realizamos busca por palavras-chave no buscador de experiências, bem como nas últimas experiências publicadas, com os seguintes termos: gestão participativa, intersetorialidade e o direito à cidade.

Realizamos um esforço no sentido de tentar identificar temas e projetos que estimulem novas atitudes ou produzam mudança significativa na vida das pessoas, das instituições de ensino e das cidades envolvidas. Por exemplo, quando falamos de gestão participativa, consideramos a efetividade desta política, na prática.

Deste modo, só é possível considerar a existência de projeto voltado à gestão participativa quando, de fato, novas atitudes são estimuladas ou se promova a participação ativa e direta dos cidadãos no que diz respeito à coisa pública. Como exemplo, destacamos a existência de um projeto em particular relativo à gestão participativa, o Nosotros proponemos. 
Da consulta e da análise dos dados obtidos depreendemos que esses três grandes temas são apenas minimamente contemplados ou mesmo inexistem nos projetos contidos no banco de experiências da AICE, demonstrando escassez de estudos nas seguintes áreas: gestão participativa, intersetorialidade e o direito à cidade. Neste último aspecto, particularmente, a questão da moradia.

Apesar de nosso esforço, reconhecemos que o trabalho possui diversas limitações, haja vista a amplitude da perspectiva da Cidade Educadora, bem como sua transversalidade e multidisciplinaridade, riquíssima, mas difícil de ser analisada exaustivamente em um único ensaio acadêmico. Nesse sentido, entendemos a Cidade Educadora não apenas como proposta pedagógica, mas também política, eis o porquê de sua amplitude.

Talvez frisemos o evidente ao qualificar a Cidade Educadora como, possivelmente, uma das propostas que mais aproxima os pupilos(as) de ações pedagógicas que expandem seus campos formativos a partir do lugar em que vivem, promovendo, por exemplo, valores culturais e a memória histórica que constituem a cidade como território do aprender.

\section{Afinal de contas, o que é Cidade?}

Antes de qualquer tentativa de tratar da Cidade Educadora, façamos um breve exercício de reflexão sobre o que é a cidade. Sobre esta, acreditamos que um mínimo de construção teórico-conceitual é necessária para fundamentarmos nossas perspectivas e compreensões acerca da cidade educadora, e, posteriormente, buscarmos não apenas respostas para as questões que norteiam a proposta deste trabalho, mas também para o avanço da própria pesquisa e extensão sob a bandeira das Cidades Educadoras.

Portanto, esse passo ligeiramente atrás, em busca de compreender o que é a cidade, deve ser considerado tarefa fundamental para darmos um salto qualitativo um pouco mais adiante, após nos situarmos na discussão municiados com as ferramentas essenciais para compreender, posteriormente, o que poderia vir a qualificar o termo cidade.

Desde logo, importa considerar não haver definição que se aplique sozinha a todas as acepções e manifestações de cidade. Nas palavras de Alves e Brandenburg (2018), não há consenso quanto a uma definição única do que seja a cidade, sobretudo considerando 
as diversas acepções possíveis de utilização e as variáveis selecionadas para determinar suas diversas manifestações, dimensões e escalas de análise.

Garbossa e Silva (2016, p. 21) afirmam que, ao se considerar o conceito de cidade, inúmeras analogias podem ser feitas, por isso, argumentam que se trata de "uma denominação que abriga inúmeros significados".

Lencioni (2008, p. 114-115) trata dessa questão afirmando que "o conceito de cidade é obscuro, pois admite um sentido semântico próprio, mas também outros sentidos que transcendem ao sentido semântico normal da palavra cidade, ou seja, permite derivações por metonímia".

Para o historiador Lewis Mumford, compreender o que é a cidade, como começou a existir, que processos promove, quais funções desempenha, que finalidades preenche, etc., não é tarefa trivial. Em sua clássica obra, A Cidade na História, o autor considera que "as origens da cidade são obscuras, [...] e são difíceis de pesar suas perspectivas futuras". (MUMFORD, 1961, p. 11).

Apesar da carga de obscuridade envolvida na compreensão do termo ou conceito de cidade, Mumford admite que as primeiras formas de fixação da sociedade no espaço foram estabelecidas em razão do culto aos mortos.

Ou seja, em algum momento na história da humanidade, percebeu-se que, para além da necessidade de domesticar animais por subsistência, era necessário saber o que fazer com os corpos humanos após a morte.

Era na eventualidade da morte que se chegava ao momento da certeza de que a matéria, de uma forma ou de outra, fixar-se-ia ao lugar. E aqui devemos abrir uns parênteses para admitir ser absolutamente natural e inevitável considerar que a matéria, neste caso o corpo humano, integra-se e se relaciona com o meio de qualquer maneira, na vida ou na morte.

Uma abordagem literária e bem interessante sobre as cidades e os mortos se encontra em Calvino (1990), a qual inspira a refletir sobre o uso dos cemitérios como abordagem didática. Mas, no contexto deste trabalho, não abordaremos diretamente a relação discutida por Calvino, igualmente relevante. Aqui, tratamos da cidade viva e pulsante, a cidade dos vivos para os vivos, por assim dizer.

Portanto, como defendia Lefebvre (2001), é na cidade que vivemos, socializamos, aprendemos, produzimos, reproduzimos nosso cotidiano no espaço vivido. É, também, no 
espaço das cidades que nossa relação com a natureza e com a sociedade se manifesta. Ou seja, nós produzimos e transformamos o espaço da cidade constantemente e, ao transformá-lo, transformamo-nos.

Como diria o sociólogo urbano Robert Park, citado por Harvey (2014, p. 28), a cidade é

A tentativa mais coerente, e em termos gerais, mais bem-sucedida de refazer o mundo em que vive, e de fazê-lo de acordo com seus mais profundos desejos. Porém, se a cidade é o mundo criado pelo homem, segue-se que também é o mundo que ele está condenado a viver. Assim, indiretamente, e sem nenhuma consciência bem definida da natureza de sua tarefa, ao criar a cidade, o homem recriou a si mesmo.

A reflexão de Robert Park pode ser facilmente associada às análises dialéticas, tais como as de Milton Santos e David Harvey. Esta perspectiva nos permite reconhecer que a humanidade atua e pode modificar o meio para satisfazer suas necessidades ou gerar riqueza, porém, paradoxalmente, ao transformá-lo, altera sua relação com o entorno, a natureza e seu próprio modo de vida.

\section{A cidade e seus diferentes rótulos}

Cidade ecológica, cidade saudável, resiliente, inteligente, sustentável, educadora, entre outras, são termos muito difundidos na atualidade e geram certa confusão quando lidos por um leigo. Exploremos um pouco essas terminologias a partir de diferentes perspectivas de análise.

Para Harrison e Donnelly (2011), cidades inteligentes ou smart cities não se referem a terminologias essencialmente novas, pois, desde o final da década de 1990 já se empregavam em relação às novas estratégias de planejamento urbano.

Conforme Weiss, Bernardes e Consoni (2015), smart cities são aquelas cidades a usar sistematicamente Tecnologias de Informação e Comunicação (TICs) para promover eficiência no planejamento, execução e manutenção dos serviços e das infraestruturas urbanas, em benefício dos atores envolvidos.

Segundo a União Europeia, citado por SECTI (2019), smart cities são sistemas de pessoas a interagir e usar energia, materiais, serviços e financiamento para catalisar o desenvolvimento econômico e a melhoria da qualidade de vida, através do recurso 
estratégico à infraestrutura e aos serviços de informação e comunicação, com planejamento e gestão urbana, em resposta às necessidades sociais e econômicas.

As cidades resilientes surgem de uma campanha lançada pela Organização das Nações Unidas (ONU) em 2010, chamada Construindo Cidades Resilientes. Segundo as Nações Unidas (2012), cidades resilientes são aquelas com capacidade para resistir, absorver, adaptar-se e se recuperar de forma eficiente dos efeitos de um perigo ou desastre, de maneira organizada e tempestiva, prevenindo a perda de vidas e de outros bens.

Tal perspectiva encontra uma relação interessante na Geografia, quando comparamos a cidade (o espaço), enquanto organismo, tal como Friedrich Ratzel. Nesse sentido, conforme argumenta Tosta (1984, p. 10), a cidade, ou até mesmo o Estado, pode "expandir-se, contrair-se, viver, prosperar, decair e morrer como seres vivos", dependendo do grau de vinculação material e imaterial entre a sociedade e o solo." (ALVES, 2015, p. 220221).

Esse entendimento encontra intersecção também na interpretação de Jane Jacobs, em sua obra publicada originalmente em 1961. Na apresentação da edição brasileira do livro de Jacobs (2011), feita por Ana Luiza Nobre, a cidade é compreendida por Jacobs a partir da

[...] movimentação das pessoas nas calçadas das ruas..., movimento este feito de gestos pequenos, anônimos e rotineiros- as crianças que vão para a escola, o comerciante que abre a loja, os estranhos que frequentam o bar, a senhora que põe o lixo na rua-, "esse balé da calçada" é executado dia e noite, sem nunca se repetir, e torna-se em grande parte responsável pela segurança da rua. (JACOBS, 2011 apud NOBRE, 2011, p. 11).

Tal interpretação alude à ideia de que alguns modelos de reestruturação ou revitalização urbana devem ser inspirados a partir do ponto de vista de quem pratica a vitalidade urbana cotidianamente. Ou seja, uma reestruturação urbana que não destruísse a história e a geografia de áreas consolidadas ao longo do tempo para dar lugar a projetos urbanos modernos, desconexos de seu tempo, sobretudo, das pessoas que usam e promovem dia a dia a transformação do espaço da cidade.

Tal concepção concede o protagonismo das transformações às pessoas que vivem a cidade, e não por meio de esquemas teóricos implementados a partir apenas do espaço contemplado em projetos que atendam exclusivamente princípios funcionalistas do 
urbanismo. Essa ideia se assemelha muito à visão de Lefebvre, quando observa que o espaço concebido nem sempre se adequa ao vivido e percebido.

A partir da interpretação de Jacobs (2011), podemos pensar no ativismo que promove as mudanças nas cidades. Ou seja, embora exista um espaço concebido, é seu uso e a prática social que, de fato, conferirão à cidade a identidade de seus bairros e dos cidadãos que os habitam.

Nesse sentido, trata-se da ocupação do espaço da cidade pelo próprio corpo do cidadão que ali vive ou, ainda, da coletividade que usa o espaço público para promover debates e discussões abertas cujo objetivo é ver transformação a partir da identificação de interesses comuns.

Contudo, ocupar o espaço da cidade dessa maneira pode ser considerado afronta ao poder constituído. Quando a coletividade não é ouvida, a ocupação talvez ocorra com "ferocidade" e manifestações de rebeldia, daí a perspectiva de Cidade Rebelde discutida em Harvey (2014). A cidade rebelde é aquela que defende o direito à cidade, e vai além, no sentido de atribuir o protagonismo da transformação e da revolução urbana ao cidadão, ao povo.

A exemplo das manifestações ocorridas na Praça Tahrir, em 2013, no Cairo, e em 2011, em Londres, Harvey (2014) ressalta que esse movimento de ocupação das ruas representa a insurgência popular contra as medidas de austeridade e o poder autoritário constituído (e não mais reconhecido).

Para o autor, trata-se de claras demonstrações de que o poder verdadeiramente deve emanar do povo, e não de governos que imponham mudanças de cima para baixo com o objetivo de atender interesses particulares, ou seja, Harvey critica fortemente o sistema econômico e financeiro atual, que considera "cruel e empedernido" (HARVEY, 2014, p. 278).

Seguindo uma vertente muito inspirada na escola lefebvriana de pensamento, Harvey discute acerca da importância da apropriação e transformação da cidade a partir da ocupação de seu espaço por meio dos corpos humanos. Segundo Harvey (2014, p. 281),

Essa tática, notavelmente reativada nas nobres e atuais lutas que se travam na Praça Tahrir, no Cairo, espalhou-se pelo mundo inteiro (Puerta del Sol, em Madri, Praça Sintagma, em Atenas, e agora nas escadarias da Catedral de São Paulo, em Londres, e na própria Wall Street). Isso nos mostra que o poder coletivo dos corpos no espaço público ainda é o 
instrumento mais eficaz de oposição quando todos os outros meios de acesso se encontram bloqueados. O que a praça Tahrir mostrou ao mundo foi uma verdade óbvia: que os corpos nas ruas e praças, e não a tagarelice sentimental do Twitter ou do Facebook, é o que realmente importa.

Essas considerações são importantes quando se busca planejar e construir a cidade que queremos, inclusive a cidade que educa. Percebe-se a cidade inevitavelmente associada ao papel que pode desempenhar, de modo que determinada cidade se insere no sistema de cidades com dada função e um rótulo, manifestando seus anseios, preocupações e interesses em graus diversos, por meio da ação (ou omissão) de seus cidadãos, gestores e assim por diante.

Para além das funções da cidade, outra maneira de buscar compreendê-la é através da seleção de determinados atributos ou características do espaço urbano e sua capacidade para se relacionar com outros territórios.

Isto posto, não é apenas o espaço físico que estamos considerando, mas também a rede de relações que a cidade estabelece a partir do movimento e da interação promovidos por cidadãos, empresas, governos, entre outros. Todavia, para examinar com mais profundidade essa perspectiva, torna-se necessário cogitar outras formas de compreender a cidade a partir de categorias distintas de análise. Conduziremos esta tarefa nas seções seguintes.

\section{A cidade como resultado de suas formas, estruturas, funções e processos}

Quando analisamos a cidade a partir de uma perspectiva que valoriza a interdependência entre sociedade e natureza, prestigiamos aquela cuja abordagem explora o conhecimento das formas, estruturas, funções e dos processos da cidade, como na análise de Santos (1985).

A partir da estrutura urbana é possível conceber a cidade segundo teorias de localização das atividades econômicas (ALVES, 2015). Alternativamente, concebê-la no contexto de uma análise sobre a hierarquia urbana, na perspectiva dos lugares centrais de Walter Christaller. Ou, ainda, mais remotamente, inspirada na teoria da renda da terra e no pioneirismo de Johann von Thünen, além de uma série de outras abordagens que envolvem 
um estudo mais aprofundado sobre a produção do espaço urbano e o sistema de cidades de modo geral.

A Geografia, o Urbanismo, a Economia e a Matemática são áreas que oferecem ricos e diferentes olhares sobre essas questões. Na perspectiva da Cidade Educadora, esse olhar para a dimensão espacial das relações na cidade requer do indivíduo atenção e interesse para ler e compreender as dinâmicas que ocorrem no espaço geográfico.

Além de aprenderem a se localizar no espaço geográfico, jovens, crianças e adultos podem desenvolver, por exemplo, a habilidade de relacionar objetos e lugares no espaço geográfico, compreender a produção do espaço urbano a partir das funções dos lugares, do zoneamento urbano, do uso e ocupação do solo para identificar problemas nos bairros, etc.

A propósito, o zoneamento é um importante instrumento de regulação da produção e transformação do espaço da cidade. Logo, por que não ensinarmos nossos pupilos a entender essa lógica espacial a partir de suas realidades, dos lugares em que vivem e exercem atividades da vida cotidiana?

Além disso, conforme veremos adiante, segundo a teoria de Johann von Thünen e da maioria dos teóricos de localização, os empreendedores ou, ainda, os particulares proprietários de terras teriam certa liberdade por localizar seus empreendimentos ou atividades econômicas na cidade, ainda que o modelo oferecesse inúmeras limitações.

Contudo, tal liberdade é relativizada, limitada pela intervenção do Estado, ou mesmo pelas ações dos governos, o que nos conduzirá a outra vertente importante na perspectiva da Cidade Educadora, a dos direitos fundamentais e sociais.

Todavia, de volta às reflexões iniciadas nesta seção e na perspectiva de Santos (1988, p. 77), outra possibilidade seria compreender a cidade reconhecendo-a como "um espaço formado de fixos e de fluxos". Fixos e fluxos são instrumentos que nos permitem compreender a cidade por categorias clássicas como produção, circulação, distribuição e consumo (SANTOS, 1988).

Fixos e fluxos representam muito mais que simples objetos fixos localizados no espaço, ou que o movimento promovido por tais fixos a partir dos fluxos que estabelecem. Em vista disto, a cidade não deve ser considerada simples aglomerado de casas ou de indivíduos, ou seja, um conjunto formado apenas por fixos. 
A cidade deve ser entendida também conforme propõem Braga e Giometti (2004, p. 3): “o lugar das trocas, do comércio, das inter-relações de pessoas e de lugares... o lugar para onde convergem os fluxos, materiais e imateriais, da sociedade, de gente, de riqueza, de poder, de saber".

Semelhantemente, a cidade pode ser entendida como sobreposição da sociedade em dado território, ou, conforme Santos (2000), como um território. No entanto, professor Milton Santos já dizia que o território "só se torna um conceito utilizável para a análise social quando o consideramos a partir de seu uso, a partir do momento em que o pensamos juntamente com aqueles atores que dele se utilizam." (SANTOS, 2000, p. 22).

Tal noção de território usado se relaciona fortemente com as ocupações em Londres, São Paulo e na Praça Tahrir. Esta clássica categoria de território (usado) permite a construção de uma cidade a partir de quem nela vive, de quem para ela trabalha, contribui e exerce cidadania.

\section{Mas, e a cidade educadora, o que vem a ser exatamente?}

Vimos que, para compreendermos a perspectiva da cidade educadora necessitamos conhecer inicialmente as diversas noções, dimensões e escalas de análise da cidade. Isto implica reconhecermos principalmente seu caráter funcional, sua importância no território.

A cidade sempre resulta da interação entre o meio e as pessoas que o habitam ou exercem atividades da vida cotidiana. Há ainda, sem dúvida, fatores externos que interferem nessa relação. De qualquer forma, entendemos ser a partir do espaço vivido que um indivíduo compreende o lugar, sua capacidade de atuação nele, bem como as transformações sofridas por processos globalizantes.

Compreender a relação entre sociedade e meio é fundamental para construir e transformar à cidade educadora, pois, dessa interação surgem discussões sobre questões como cidadania, gestão participativa e aprendizagem relacionada ao espaço vivido.

Assumindo essa concepção, consideramos inicialmente a cidade educadora segundo Lefebvre (2001), que define cidade como espaço ou território educativo. Outrossim, Farfus (2011) admite que a cidade educadora tem por base formar cidadãos 
conscientes de seu papel e do exercício pleno da cidadania, contextualizando questões de desenvolvimento local e global e suas influências na formação social.

Outra acepção comumente encontrada na literatura sobre cidade educadora é aquela que a considera de maneira semelhante aos territórios educativos, ainda que o termo território possua carga bastante distinta quando analisada em relação ao termo cidade. Em comum, cidades educadoras e territórios educativos abarcam a ideia de que a educação não deve se restringir à aprendizagem escolar.

A educação deve ocorrer em todos os cantos de uma comunidade. A escola, nesse contexto, não apenas se insere na comunidade, como é parte importante e capaz de transformar seu entorno. A partir dessa perspectiva, em 2007, criou-se o programa federal Mais Educação. O Mais Educação implementou educação em 60 mil escolas públicas brasileiras, a partir da extensão da jornada escolar e da ampliação qualificada das oportunidades de aprendizagem.

O programa colocou o território educativo no centro do debate sobre a formação de crianças e de adolescentes no Brasil. A respeito dessa temática, uma das pesquisadoras mais influentes é a professora Jaqueline Moll, que trouxe discussões muito importantes para a construção de uma educação integral de qualidade e em tempo integral, apesar de reconhecer os enormes desafios e avanços relacionados às estratégias indutoras de ações e políticas nessa perspectiva (MOLL; LECLERC, 2012).

O território educativo pode ser considerado como qualquer espaço público acessível, desenhado para melhorar a qualidade de vida, a saúde e o bem-estar das pessoas. Esse espaço pode ser uma praça, um clube comunitário, um teatro, um museu, uma igreja ou até mesmo as próprias ruas da localidade. Há uma infinidade de espaços públicos que podem ser utilizados como territórios educativos.

Ainda que não concordemos com a totalidade de sua afirmação, Serpa (2007, p. 15), em seu livro, considera que "a Geografia pouco se ocupou da discussão acerca do espaço público urbano". Para este autor, alguns temas são importantes de serem revisitados quando alguém se propõe a analisar a apropriação social do espaço público na cidade contemporânea.

Entre esses temas, o autor se dedica a análise da acessibilidade no espaço público urbano; da valorização imobiliária (com o papel do parque público na revitalização/requalificação de bairros em crise); da visibilidade, com ênfase no que se deve 
mostrar e no que se deve esconder; do turismo e da espetacularização, com uma cidade festiva, o consumo cultural; da natureza e da intersubjetividade, como caminhar na paisagem; a cultura e a participação popular, entre outros.

É notável que muitos geógrafos renomados se debruçaram sobre esses e outros temas, sob diversas perspectivas, tais como em Harvey (1973; 2014); Lencioni e Carlos (1982); Trindade Júnior (1998); Carlos (2007); Firkowski (2015). De qualquer forma, concordamos plenamente que a abordagem de Serpa (2007) enfoca questões por vezes obscurecidas devido à rapidez da sucessão dos fatos e eventos do cotidiano urbano, como os diversos interesses e as políticas, ou, ainda, pela ausência de uma cultura de contemplação das paisagens urbanas.

Nesse sentido, a abordagem de Serpa é muito interessante ao tentar compreender as qualidades norteadoras da apropriação social do espaço público na cidade contemporânea, "buscando explicar como espaços, que, em tese, seriam — ou deveriam ser - acessíveis a todos, vão sendo apropriados de modo seletivo e diferenciado pelos diferentes agentes e grupos." (SERPA, 2007, p. 10).

Com esse olhar para a cidade como um espaço público, pode-se repensa-la como local que possibilita socialização e diferentes experiências de aprendizado além das instituições educacionais convencionais, valorizadas pelo modelo tradicional que ocorre apenas no ambiente formal da escola, o qual passou a ser questionado.

A cidade deve ser compreendida como um agente educativo, e assim foi entendida pelas diferentes civilizações. "Um lugar onde as pessoas se reúnam para conviver, para aprender, para participar da vida social e para exercer seus direitos de cidadãos." (GÓMEZGRANELL; VILLA, 2003). Mas, como se pode imaginar, mudar um paradigma não é tarefa executada rapidamente.

Conforme afirma Dewey (1979), citado por Tascheto, Marcon e Mella (2019, p. 102), na tentativa de conceber uma nova filosofia da educação baseada em experiências democráticas, "é muito mais difícil gerir espaços educativos baseados em uma nova ordem de conceitos do que conduzir a gestão de espaços que seguem velhos caminhos, visto que uma nova configuração de gestão corresponde a criar também novas práticas, abandonando a tradição e o costume".

A compreensão de cidade como território do aprender vai além do ambiente vivido e percebido. É o lugar onde crianças, jovens e adultos tomam consciência de sua 
capacidade de ação para transformar o ambiente e, ao assim pensarem e agirem, podem conceber a cidade a partir de suas próprias realidades, experiências, interação com o meio em que vivem, etc.

Portanto, em nosso entendimento, a cidade educadora não é apenas uma proposta pedagógica, mas também política, capaz de transformar bairros, escolas e comunidades inteiras. Sem dúvida se trata de proposta que conduz à aprendizagem significativa, mas não deve ter como única finalidade compreender a cidade a partir de mera observação da interação entre sociedade e meio.

Essa interação é importante para a construção de uma cidade educadora, mas não é apenas para esse fim que os muros da escola devem ser ultrapassados. A capacidade de agir deve ser integrada às de pensar e contemplar as paisagens, ou seja, há que se atribuir protagonismo aos aprendentes de modo que reconheçam que não apenas vivem no espaço, como também podem transformá-lo.

Na cidade educadora, compreender a interação entre sociedade e meio a partir do lugar, e da tríade lefebvriana do espaço concebido, vivido e percebido é uma alternativa relevante para se pensar, agir e produzir a transformação desejada. Para tanto, essas três dimensões devem ser consideradas indissociáveis quando alguém se propõe a analisar a produção do espaço, ainda que "uma dimensão possa se projetar sobre as outras, ocultando-as." (ALVES, 2019, p. 562).

Nesse sentido, entendemos que a cidade educadora está entre aquelas poucas, porém, valiosas e resistentes propostas que mais aproxima o indivíduo do entendimento acerca de como ocorre a produção e a transformação do espaço a partir do lugar, e de que maneiras o próprio indivíduo, as escolas, as instituições, as comunidades, entre outras, podem participar efetivamente e contribuir com essas transformações.

Entretanto, se temos que definir um rótulo ou conceito para a cidade educadora, adotaremos aquele proposto pela Associação Internacional de Cidades Educadoras (AICE). De acordo com a Carta das Cidades Educadoras (AICE, [s.d.]), a cidade educadora pode ser entendida como aquela que, além de suas funções tradicionais, reconhece, promove e exerce um papel educador na vida dos sujeitos, assumindo como desafio permanente a formação integral de seus habitantes. Na Cidade Educadora, as diferentes políticas, os espaços, os tempos e os atores são compreendidos como agentes pedagógicos, capazes de apoiar o desenvolvimento de todo potencial humano. 
Conforme veremos adiante, é importante considerar que todos esses rótulos de cidade analisados até agora (inclusive o da cidade educadora) estão relacionados, em maior ou menor grau, ao marketing da cidade. E, mais especificamente, à imagem que se procura transmitir da cidade para ser não apenas concebida, vivida e percebida, mas também consumida.

\title{
O surgimento da perspectiva da cidade que educa (e que aprende)
}

Há mais de três décadas, em 1990, ocorreu o I Congresso Internacional de Cidades Educadoras, em Barcelona (Espanha). Contudo, esse movimento só se consolidou quatro anos depois, em Bolonha (Itália), na ocasião do III Congresso Internacional de Cidades Educadoras, quando da criação da Associação Internacional de Cidades Educadoras - AICE (ALVES; BRANDENBURG, 2018).

Em 1994, aprovou-se a primeira versão da carta das cidades educadoras, que representa o compromisso pela construção de cidades mais inclusivas, justas e participativas, com destaque para a criação de mecanismos que permitam às crianças e aos adolescentes vivenciarem plenamente sua cidadania.

Entretanto, a perspectiva de se aprender com a cidade, sobre a cidade, e para a cidade não é necessariamente nova. Conforme enfatiza Bernet (1997, p. 13),

\begin{abstract}
la expresión ciudad educativa se ha popularizado extraordinariamente desde hace unos años, pero la idea que contiene puede, sin duda, rastrearse en pedagogías muy antiguas, Por supuesto seria obligatorio referirse a la relación íntima que se establecía en la Grecia clásica entre la paideia y la polis. O también, por ejemplo, habría que citar las utopías renacentistas que se diseñaban ciudades ideales en las que la educación jugaba un papel fundamental.
\end{abstract}

No entanto, grosso modo, podemos considerar relativamente nova, nas palavras de Carbonell (2016, p. 19), a “sistematização do modelo", ou seja, a organização de propostas político-pedagógicas e eixos temáticos explorados a partir da relação cidadeescola (ou vice-versa) no âmbito da Associação Internacional de Cidades.

Com essas considerações em mente sobre a cidade e suas funções, passaremos aos contextos fundamentais nos quais a perspectiva da cidade educadora emergiu e se 
desenvolve, tarefa importante para compreendermos as atuais iniciativas, os projetos inovadores e as ações empreendidas sob a bandeira da cidade educadora.

\section{Contextos fundamentais a serem analisados no surgimento e desenvolvimento da perspectiva da Cidade Educadora}

Iniciaremos esta seção a tratar do amplo contexto da urbanização mundial. Conforme expusemos no início deste artigo, em 2014, cerca de 50\% da população mundial era urbana. Contudo, segundo a Nações Unidas (2015), a perspectiva para 2050 é de cerca de $66 \%$ da população mundial em áreas urbanas e $34 \%$ em áreas rurais. Isto é, a urbanização continuará a gerar crescentes implicações importantes a serem pensadas pelas cidades de todo mundo, sobretudo, aquelas que assumem a bandeira das Cidades Educadoras.

Isso decorre do fato de a urbanização aumentar a demanda por serviços públicos, por infraestrutura, acessibilidade, mobilidade, moradia, emprego, saúde, educação, entre outros. Logo, pensar nessas questões se torna tarefa fundamental a ser desempenhada nos projetos atualmente conduzidos sob a bandeira das cidades educadoras, tais como o Superilla Barcelona e o Nosotros proponemos.

Outro contexto importante é o da industrialização. Sem dúvida, a presença da indústria em determinado território é por vezes considerada fator de desenvolvimento, além de ser "importante agente produtor do espaço" (ALVES; ANTUNES, 2019, p. 28).

Entretanto, como dizia o venerável mestre professor Mario Alencastro (2012), a atividade industrial corrobora também para o surgimento do movimento ambientalista, haja vista sua capacidade para poluir e provocar doenças.

Recordando a publicação do relatório feito pelo Clube de Roma em 1972, intitulado Os limites do crescimento, Alencastro argumenta que o crescimento da produção industrial e da economia poderiam acarretar "num espaço de tempo relativamente curto, numa catástrofe nos fundamentos naturais da vida, ou seja, o consumo voraz de recursos e a emissão descontrolada de poluentes estariam comprometendo a sobrevivência da humanidade." (ALENCASTRO, 2012, p. 26).

A internacionalização das cidades e o processo de globalização são outros dois contextos relacionados a implicações para as cidades ou, se preferir, para os lugares. Apesar de relacionados, globalização e internacionalização são dois conceitos distintos. 
Para Santos (2013, p. 45) a globalização é “o estágio supremo da internacionalização, a amplificação em sistema mundo, de todos os lugares e de todos os indivíduos, embora em graus diversos". Ou seja, a globalização se refere à crescente integração das diferentes partes do mundo, sob o efeito da aceleração das trocas, do impulso de novas tecnologias de informação e comunicação, dos meios de transporte, etc. (SANTOS, 2013).

Nessa perspectiva, uma possibilidade seria admitir a cidade além do lugar, isto é, uma cidade que se aproxima muito mais do global e das conexões que extrapolam os limites territoriais das cidades tradicionais. A partir desse ponto de vista, algumas cidades são cosmopolitas e podem ser entendidas também como cidades-regiões globais, como nas obras de Scott (2001), Sassen (1991) e Storper (1997).

A cidade empreendedora é outro reflexo do modelo que procura se adaptar às demandas impostas pelo global (HARVEY, 2006). Nesse tipo de cidade, adotam-se estratégias mais flexíveis de gestão e a globalização acaba por impor um novo modelo para a cidade, em que a gestão administrativa cede espaço ao modelo de gestão empreendedora.

Obviamente, o que se revela aqui é a redução do papel do Estado de bem-estar social, das políticas assistencialistas e do Estado que se preocupa com o pleno emprego. Nesse modelo de gestão, o Estado deixa de ser o principal provedor de serviços públicos, de infraestrutura, de educação, saúde, entre outros. Ademais, intensificam-se as parcerias público-privadas.

Portanto, a cidade precisa ter os atributos necessários para atrair eventos, além de ser eficiente, desenvolver tecnologia, ciência, conhecimento e permitir o consumo nos moldes impostos pelo capitalismo. Observa-se uma "competição entre lugares", como diria Santos (2000, p. 57).

No contexto da gestão empreendedora e de competição entre lugares, a discussão da cidade como mercadoria é praticamente inevitável. Por isso, surge o marketing da cidade e sua mercantilização. E é exatamente neste último contexto que finalizamos a ideia de que o marketing da cidade contribui para alocação de determinados eventos e investimentos em determinados lugares no amplo espaço globalizado.

Tal cenário ensejou a participação de Londres como sede das olimpíadas de 2012 (ALVES, 2012), do Rio de Janeiro, em 2016, e da Copa do Mundo em Curitiba, em 2014. 
Semelhantemente, Barcelona sediou as olimpíadas em 1992. Obviamente, o marketing da cidade sempre esteve lá para incentivar a realização de megaeventos esportivos, atrair investimentos e proporcionar visibilidade às cidades.

Com Barcelona não seria diferente. Cidade-sede da AICE, Barcelona também se inseriu nesse circuito do capital. Não esqueçamos da majestosa apresentação de Freddie Mercury e Montserrat Caballé quando da candidatura e promoção da cidade de Barcelona para sediar o grande evento das olimpíadas de verão de 1992.

O álbum Barcelona, de 1988, foi uma das últimas produções de Freddie, que faleceu em 1991. De fato, o evento de abertura das olimpíadas de 1992, em Barcelona, contou com a música de Freddie e Montserrat, escolhida como hino para o evento. Dois anos depois, em 1994, fundou-se a AICE.

\section{Projetos inovadores e lacunas de pesquisa na perspectiva das Cidades Educadoras}

Na introdução deste artigo deixamos implícita a ideia de que poucas pesquisas se debruçaram com o propósito de compreender a cidade educadora a partir dos diferentes usos que os indivíduos fazem do solo urbano, sobretudo, para satisfazer necessidades de habitação, cumprir (e respeitar) o direito à moradia. Ao menos essa é a conclusão ao analisarmos o banco de experiências contido no site da AICE.

Isto posto, entendemos que algumas limitações são bastante visíveis e merecem sinalização desde logo. Assim, apoiados nas consultas e análises do banco de experiências da AICE, depreendemos lacunas de pesquisa para apreciação e preenchimento na perspectiva das Cidades Educadoras.

Ao argumento relativo à habitação e ao direito à moradia, acrescentamos agora que o zoneamento, o uso e ocupação do solo também são reflexos das maneiras com as quais nos relacionamos com a natureza, seja para viver, consumir produtos e serviços, planejar, construir ou transformar a cidade que queremos. Há riqueza de projetos a explorar no âmbito das Cidades Educadoras, muitos adaptáveis à realidade de cidades localizadas em diversos países, quer sejam desenvolvidos, em desenvolvimento, em transição, emergentes, entre outros.

Importante destacar ainda que a habitação e a moradia são termos que se referem novamente à fixação do indivíduo ao lugar, e, consequentemente, à ideia de pertença, do 
exercício dos direitos sociais e da identidade estabelecida em relação ao espaço da cidade. Para além desses aspectos há o princípio da dignidade da pessoa humana, daí também a relevância que a questão da moradia merece no contexto da Cidade Educadora.

Destacamos essa lacuna justamente por haver sérios problemas a enfrentar relacionados ao direito à moradia e sua relação com a Cidade Educadora. Existem cidades brasileiras que estão sob o manto da Cidade Educadora, mas cujos governos apresentam dificuldades para atender crianças e jovens inseridos em contextos socioeconômicos desfavoráveis, por vezes em condição de vulnerabilidade.

Tenha como exemplo aqueles pais, avós, mães solteiras, desempregados, entre outros, que no contexto da pandemia não conseguiram mais pagar o aluguel e se sujeitaram a morar em ocupações irregulares. É certo que esse problema está inserido em um contexto mais amplo, do capitalismo mundial e de especulação imobiliária. Contudo, isso não exime à administração pública e os governos de cumprir suas responsabilidades.

As crianças e jovens que vivem nessas ocupações precisam estudar. Como o problema é tratado? Nesses casos, a educação não ocorre em espaços formais, mas com voluntários, pois, do contrário, essas crianças e jovens estariam nas ruas a viver embaixo de pontes e viadutos, sujeitos a condições ainda mais vulneráveis.

Veremos que a questão da moradia, bem como a da gestão participativa, insere-se em ampla discussão em torno do direito à cidade. Embora figurem como temas de interesse no âmbito da Associação Internacional de Cidades Educadoras, é notável que poucas pesquisas se dedicaram a compreender a cidade educadora por meio desses vieses.

Apesar da escassez de estudos, algumas iniciativas ou projetos inovadores são louváveis. Vamos explorar dois casos. O primeiro deles, o projeto Superilla ou Superblock Barcelona. Implementado no distrito de Grácia, apresenta interseções com várias temáticas atuais, tais como associativismo e participação, cidadania, desenvolvimento urbano e qualidade de vida urbana.

Trata-se de projeto dirigido a vários grupos etários, não apenas crianças e adolescentes. E, aqui, importante trazer um pressuposto contido na Carta de Cidades Educadoras, qual seja, o de que a cidade educadora, ao objetivar a formação, promoção e o desenvolvimento de todos os seus habitantes, "deve se ocupar prioritariamente com as crianças e jovens, mas com a vontade decidida de incorporar pessoas de todas as idades, numa formação ao longo da vida." (AICE, [s.d.], p. 2). 
O Projeto Superilla foi iniciado em 2006, e, em tese, encerrado em fevereiro de 2021, conforme apresenta o banco de experiências da AICE. A grande contribuição deste projeto diz respeito a redução dos índices de poluição gerados por automóveis na cidade, iniciativa pela qual ganhou o prêmio Best Practice, do UN-Habitat, em 2018.

Apesar de inovadora, a iniciativa é bastante simples e permite transformação profunda das localidades envolvidas no projeto, haja vista não requerer grandes investimentos econômicos para construção de estruturas ou demolições. Em vez de veículos, os espaços são apropriados para pessoas, caminhadas, descanso, brincadeiras e atividades comunitárias, ao mesmo tempo em que as áreas verdes são ampliadas.

Importante recordarmos que o projeto Superilla se assemelha muito a um projeto bastante antigo e extremante inovador de 1972, em Curitiba, durante o primeiro mandato do então prefeito, o arquiteto e urbanista Jaime Lerner. Estamos nos referindo à Rua XV de Novembro, considerada a primeira grande via pública exclusiva para pedestres do Brasil. Nesse sentido, Curitiba já continha vários atributos que poderiam enquadra-la como importante Cidade Educadora, pioneira em questões de mobilidade, acessibilidade, meio ambiente, etc.

Outro projeto que consideramos de enorme importância para a gestão participativa é o Nosotros proponemos, um dos poucos a minimizar a escassez de estudos e pesquisas sobre uso e ocupação do solo na perspectiva das Cidades Educadoras. Isto é, sobre aquele espaço vivido na cidade relacionado a diferentes usos, que, no que thes concerne, delimitam-se política, jurídica e geograficamente.

O projeto Nosotros proponemos permite saber porque no bairro $\mathrm{X}$ se promove tal atividade, ou as razões pelas quais, na localidade $\mathrm{Y}$, as atividades são diversas. Estas geralmente envolvem o estudo de teorias, conceitos e cartografia em espaços formais de educação, bem como o planejamento e a execução de aulas de campo, em que os pupilos(as), jovens e adultos, investigam e identificam problemas da cidade e podem propor soluções.

Em outras palavras, o indivíduo protagoniza seu aprendizado, e entende como a aprendizagem significativa ocorre a partir da observação, experimentação e percepção dos problemas presentes em contextos locais. Tal aprendizagem está fortemente relacionada ao conhecimento do território, do zoneamento urbano, do uso e da ocupação do solo, os quais são determinados por legislação específica. 
Segundo Rodriguez-Domenech (2018, p. 19), o projeto surge como "resposta dada pela educação às dinâmicas de globalização e a sociedade do conhecimento". Apesar de ganhar evidência com as experiências conduzidas em Évora (Portugal), em 2012, Nosotros proponemos começou realmente em 2011.

Conforme relata o Professor Claudino (2018), na Espanha, o projeto passou a ser desenvolvido entre 2016 e 2017, colocado em prática pela Faculdade de Educação da Cidade Real de Universidade Castilla — La Mancha (UCLM) e pela Prefeitura de Cidade Real (Ciudad Real), com enorme contribuição da professora Rodriguez-Domenech. A essa altura, o projeto já alcançava Portugal, Espanha e Brasil, que também já contavam com a iniciativa desde 2016.

Trata-se de um projeto com experiências que podem ser muito ricas, permitem conhecer o lugar, para que, a partir dele, possamos nos identificar com seus elementos, formas, estruturas, processos. Além disso, para que possamos identificar problemas e propor soluções à cidade, saber viver e ter a consciência de que todos (estudantes, comunidades, escolas, instituições, governos) somos capazes de construí-la e transformála.

No que concernem às lacunas de pesquisa, identificamos, portanto, a gestão participativa como importante eixo temático a ser amplamente explorado, ainda que projetos como o Nosotros proponemos sejam bastante representativos e inspiradores como proposta que preenche essa lacuna.

Outra lacuna importante se refere ao papel da intersetorialidade na municipalidade em prol de projetos no âmbito das Cidades Educadoras. Costuma-se perceber, nos projetos, iniciativas restritas às instituições de ensino e sua relação com as escolas ou, ainda, iniciativas de escolas promovidas por secretarias estaduais e municipais de educação, de modo que o engajamento, a função e a divisão de tarefas envolvendo os diversos setores governamentais ainda são pouco publicizados.

Essa não é mera observação, mas afirmação que denota uma quebra de paradigma. Certamente, pensar a cidade educadora apenas a partir do esforço de gestão das secretarias estaduais e municipais de educação não é o que se busca de uma cidade que pretende educar seus cidadãos de forma integral, humana e participativa. A formação integral começa e perpassa também, inevitavelmente, o envolvimento de toda a gestão municipal, do esforço coletivo. 
Sem dúvida, as secretarias de educação exercem papel diferenciado e por vezes protagonista nesse contexto. Entretanto, sem o envolvimento da municipalidade como um todo, a cidade educadora que se pretende construir, consolidar e alavancar será pouco original, engajadora e sustentável. Daí a importância da intersetorialidade, isto é, todos os setores engajados e cientes do compromisso que a cidade assumiu vinculada ao rótulo ou a bandeira da cidade educadora.

Por fim, falaremos do direito à cidade e, neste amplo eixo temático, o direito à moradia, outro tema bastante negligenciado na perspectiva da cidade educadora. Essa observação não deve ser entendida como crítica a escassez de iniciativas, mas oportunidade de explorar um tema que oferece insights para várias questões sociais, econômicas, ambientais, além de oferecer o cenário ideal para fortalecer o sentimento de pertença e a identificação dos cidadãos com o lugar.

Como curiosidade, a perspectiva do direito à cidade é mais velha que a da Cidade Educadora. Datada de 1968, originou-se em um contexto de "uma Paris incendiária, onde uma onda de protestos contra as reformas educacionais, iniciada pela juventude, e que culminou em uma greve geral, mobilizando toda a população da capital francesa". (DIREITO..., 2018, [n.p.]).

O livro publicado por Henri Lefebvre, em 1968, representa o marco ou a bandeira na luta pelo direito à cidade nos estudos urbanos. Consequentemente, difundiu-se na sociologia, no direito, na geografia, história, entre outras áreas. Lefebvre criticava e desafiava os gestores públicos e os urbanistas, incentivava-os a pensar a cidade como lugar de encontro, reunião e simultaneidade, cujo valor é o de uso e não o de troca.

Agora que já elencamos algumas questões ou temas que consideramos lacunas de pesquisa em projetos conduzidos sob a bandeira das Cidades Educadoras, podemos retornar a um dos argumentos discutidos anteriormente, qual seja, o de que a liberdade dos indivíduos passa a ser relativizada, limitada pela intervenção do Estado. Tal limitação nos conduz a outra vertente importante na perspectiva da Cidade Educadora, a do eixo temático dos direitos fundamentais e sociais.

No entanto, conforme também destacamos, os direitos fundamentais e sociais, particularmente o direito à moradia e à liberdade, devem ser considerados com cautela, segundo questões legais ou jurídicas. Por exemplo, ainda que o artigo $5^{\circ}$ da Constituição da República expressamente estabeleça garantia aos brasileiros, bem como aos 
estrangeiros residentes no país, de inviolabilidade do direito à vida, à liberdade, à igualdade, à segurança e à propriedade, o Estado pode intervir e limitar alguns direitos.

Daí a importância da valorização da dimensão jurídica ou legal envolvendo a produção do espaço da cidade e sua compreensão pelas crianças, pelos jovens e adultos. Esse entendimento é fundamental aos indivíduos para saberem que conhecer, produzir e transformar a cidade que educa exige compreensão da lógica de produção do espaço, dos fatores que permitem ou limitam a transformação a partir de instrumentos legais.

Uma sólida fundamentação relativa às discussões sobre direitos e deveres ampliará perspectivas e compreensões acerca da realidade, para uma ação consciente das potencialidades da cidade educadora sobre o espaço vivido, examinando não apenas suas formas, seus conteúdos, seus fluxos, mas também possibilidades do exercício do sentimento de pertença, de participação popular e gestão participativa.

\section{CONSIDERAÇÕES FINAIS}

Esta análise nos oferece diversos insights para reflexão mais profunda e criteriosa. De maneira sucinta, o trabalho abordou algumas questões importantes na concepção das Cidades Educadoras, tais como a origem da cidade e da própria perspectiva das Cidades Educadoras.

Tratamos também dos contextos fundamentais nos quais essa perspectiva emergiu e atualmente se desenvolve, bem como defendemos o argumento de que a Cidade Educadora é uma proposta política e pedagógica transformadora da educação do século 21.

De maneira exploratória, investigamos e identificamos a escassez de estudos em três eixos temáticos propostos no âmbito dessa perspectiva, quais sejam, a gestão participativa, a intersetorialidade e o direito à cidade, particularmente a questão da moradia neste último aspecto. Assim, após transitarmos por diversas vias relacionadas à perspectiva das Cidades Educadoras, podemos tecer algumas considerações a respeito dos temas e questões levantadas.

Como entendemos que a Cidade Educadora talvez seja uma das propostas que mais aproxima os pupilos(as) de ações pedagógicas que expandem seus campos formativos a partir do lugar em que vivem, promovendo, por exemplo, valores culturais e 
a memória histórica que constituem a cidade como território do aprender, não importa se o conceito de cidade é obscuro. Ademais, não importa a diferença existente entre uma cidade educadora, uma cidade resiliente, uma cidade inteligente, uma cidade ecológica, uma cidade saudável ou uma cidade sustentável.

Independentemente da confusão que isso possa gerar no leitor, é importante salientar que, além das diversas funções e rótulos da cidade, outra maneira de buscar compreendê-la é por meio da seleção de determinados atributos do espaço urbano e sua capacidade para se relacionar com outros territórios.

Portanto, se qualquer espaço público acessível é considerado território educativo, concebido ou desenhado para melhorar a qualidade de vida, a saúde e o bem-estar das pessoas, verificou-se que tal lugar pode ser uma praça, um clube comunitário, um teatro, um museu, uma igreja ou até mesmo as próprias ruas da localidade.

Identificaram-se três dimensões indissociáveis quando alguém se propõe a analisar à produção do espaço, a chamada tríade lefebvriana do espaço concebido, vivido e percebido, como alternativa para se pensar, agir e produzir a transformação desejada. Nesse ponto, vimos que a questão da moradia, bem como a da gestão participativa, inserem-se em uma ampla discussão sobre direito à cidade.

Todavia, a pesquisa sobre as cidades educadoras não deve parar por aqui. Muito há para pesquisar e propor melhorias à vida das pessoas. Além disso, é crucial o engajamento de comunidades, governos, instituições, empresas, entre outros, em prol da qualidade de vida e da formação integral dos indivíduos que vivem em grandes centros urbanos.

Enfim, não é possível afirmar que a perspectiva da Cidade Educadora se firmará como paradigma emergente pelos anos vindouros, mas, sem dúvida, trata-se de arena riquíssima para promover discussões calorosas, bem como projetos e ações para implementar melhorias.

Indubitavelmente, muitos argumentos defendidos em nossa análise ainda necessitam de aprofundamento conceitual, teórico, metodológico e empírico, de modo que trabalhos futuros poderão permitir o avanço de novas ideias nesse contexto. Tais trabalhos poderão contribuir no sentido de fornecer respostas (distintas ou não) para as questões aqui levantadas, buscando suprimir ou minimizar suas limitações. 
De qualquer forma, caso este trabalho sirva para mostrar um olhar distinto sobre a cidade que educa, isto é, algumas nuances, lacunas, perspectivas analíticas distintas, oportunidades para novas ideias, empreendimentos e projetos, nossas expectativas estarão plenamente satisfeitas.

\section{REFERÊNCIAS}

ALENCASTRO, Mário S. C. Empresas, ambiente e sociedade: introdução à gestão socioambiental corporativa. Curitiba: InterSaberes, 2012.

ALENCASTRO, Mário S. C. Ética e meio ambiente: construindo as bases para um futuro sustentável. Curitiba: InterSaberes, 2015.

ALVES, Alceli Ribeiro; ANTUNES, Eloisa M. Geografia industrial. Curitiba: Intersaberes, 2019.

ALVES, Alceli Ribeiro; BRANDENBURG, Elena Justen. Cidades educadoras: um olhar acerca da cidade que educa. Curitiba: Intersaberes, 2018.

ALVES, Alceli Ribeiro. Geografia econômica e geografia política. Curitiba: Intersaberes, 2015 .

ALVES, Alceli Ribeiro. Olimpíadas de Londres de 2012: considerações sobre a questão regional e a organização da comunidade à luz dos debates acerca dos megaeventos. Copa em discussão, Curitiba, Ano II, n. 15, 30 de novembro de 2012. Disponível em:

https://www.researchgate.net/publication/305490716_Olimpiadas_de_Londres_de_2012_ consideracoes_sobre_a_questao_regional_e_a_organizacao_da_comunidade_a_luz_dos _debates_acerca_dos_megaeventos. Acesso em: 18 ago. 2021.

ALVES, Glória da A. A produção do espaço a partir da tríade lefebvriana concebido/percebido/vivido. Geousp - Espaço e Tempo (online), São Paulo, v. 23, n. 3, p. 551-563, dez. 2019. DOI https://doi.org/10.11606/issn.2179-0892.geousp.2019.163307

ASSOCIAÇÃO INTERNACIONAL DE CIDADES EDUCADORAS (AICE). Banco de experiências. [s.l.], [s.d.]. Disponível em: https://www.edcities.org/pt/banco-de-experiencias/. Acesso em: 18 ago. 2021.

ASSOCIAÇÃO INTERNACIONAL DE CIDADES EDUCADORAS (AICE). Carta das Cidades Educadoras. Edcities.org. 2004. Disponível em: https://www.edcities.org/redeportuguesa/wp-content/uploads/sites/12/2018/09/Carta-das-cidades-educadoras.pdf. Acesso em: 18 ago. 2021. 
BERNET, Jaume Trilla. Cidades Educadoras: bases conceptuales. In: ZAINKO, M. A. S. Cidades Educadoras. Curitiba: Ed. da UFPR, 1997. p. 13-34.

BRAGA, Roberto; GIOMETTI, Analúcia B. R (orgs.). Pedagogia cidadã. Cadernos de Formação: Ensino de Geografia. São Paulo: UNESP-PROPP, 2004.

BRANDENBURG, Elena Justen Grandes projetos urbanos: vetores de desigualdade socioespacial? Análise prospectiva dos impactos e legados socioespaciais da Copa de 2014 em Curitiba. 2014. 293 f. Dissertação (Mestrado em Geografia) — Universidade Federal do Paraná, Curitiba, 2014.

BRASIL. [Constituição (1988)]. Constituição da República Federativa do Brasil de 1988. Brasília, DF: Presidência da República, [2020]. Disponível em:

http://www.planalto.gov.br/ccivil_03/constituicao/constituicao.htm. Acesso em: 18 ago. 2021.

CALVINO, Italo. As cidades invisíveis. São Paulo: Companhia das Letras, 1990.

CARBONELL, Jaume. Pedagogias do século XXI: bases para a inovação educativa. 3. ed. Porto Alegre: Penso, 2016.

CARLOS, Ana. F. A. O espaço urbano: novos escritos sobre a cidade. São Paulo: FFLCH, 2007.

CLAUDINO, Sergio. Prólogo. Gracias, queridos amigos de Ciudad Real. In: CLAUDINO, Sergio; RODRIGUEZ-DOMENECH, Maria A. R. Nosotros proponemos! Ciudadania, sostenibilidad e innovación geográfica ante los desafíos educativos de la sociedad. Barcelona: Graó, 2018.

CLAUDINO, Sergio; RODRIGUEZ-DOMENECH, Maria A. R. Nosotros proponemos! Ciudadania, sostenibilidad e innovación geográfica ante los desafíos educativos de la sociedad. Barcelona: Graó, 2018.

CURITIBA. Lei n. ${ }^{\circ}$ 15.511, 10 de outubro 2019. Dispõe sobre o zoneamento, uso e ocupação do solo no Município de Curitiba e dá outras providências. Curitiba: Prefeitura Municipal de Curitiba, 10 out. 2019. Disponível em: https://mid.curitiba.pr.gov.br/2020/00304472.pdf. Acesso em: 18 ago. 2021.

DEWEY, John. Democracia e educação: introdução à filosofia da educação. 4. ed. São Paulo: Nacional, 1979.

DIREITO à cidade. Educação e Território. 11 mai. 2018. Disponível em: https://educacaoeterritorio.org.br/glossario/direito-a-cidade/. Acesso em: 18 ago. 2021.

FARFUS, Daniele. Espaços educativos: um olhar pedagógico. Curitiba: InterSaberes, 2011. 
FIRKOWSKI, O. L. C. F. A copa do Mundo de 2014 e as transformações me Curitiba: intenções e ações. In: FIRKOWSKI, O. L. C. F.; BALISKI, P. (orgs.). Curitiba, os impactos da copa do mundo 2014. Curitiba: Kairós Edições, 2015.

GARBOSSA, Renata Adriana; SILVA, Rodolfo dos Santos. O processo de produção do espaço urbano: impactos e desafios de uma nova urbanização. Curitiba: InterSaberes, 2016.

GÓMEZ-GRANELL, Carmen; VILLA, Ignácio. A cidade como projeto educativo. Porto Alegre: Artmed, 2003.

HARRISON, Colin; DONNELLY, Ian A. A theory of smart cities. In: 55th ANNUAL MEETING OF THE ISSS, 55., 2011, Hull. Proceedings... Hull, v. 55, n. 1, 2011. Disponível em:

https://journals.isss.org/index.php/proceedings55th/article/view/1703. Acesso em: 18 ago. 2021.

HARVEY, David. A produção capitalista do espaço. 2. ed. São Paulo: Anablume, 2006.

HARVEY, David. Cidades rebeldes: do direito à cidade à revolução urbana. São Paulo: Martins fontes, 2014.

HARVEY, David. Social justice and the city. Baltimore: Johns Hopkins University Press, 1973.

JACOBS, Jane. Morte e vida de grandes cidades. 3. ed. São Paulo: WMF Martins Fontes, 2011.

LEFEBVRE, Henri. O direito à cidade. São Paulo: Centauro, 2001.

LENCIONI, Sandra; CARLOS, Ana F. A. Alguns elementos para a discussão do espaço como mercadoria. Borrador Teoria e Método, São Paulo, v. 1, p. 1-9, 1982.

LENCIONI, Sandra. Observações sobre o conceito de cidade e urbano. GEOUSP Espaço e Tempo (online), [s.I.], v. 12, n. 1, p. 109-123, 2008. DOI http://orcid.org/0000-0003-3473-0880

MOLL, J.; LECLERC, G. F. E. Programa Mais Educação: avanços e desafios para uma estratégia indutora da educação integral e em tempo integral. Educar em Revista, Curitiba, n. 45, p. 91-110, jul./set. 2012. DOI https://doi.org/10.1590/S0104-

40602012000300007

MUMFORD, Lewis. The city in history. New York: Harcourt, Brace \& World, 1961.

NAÇÕES UNIDAS. Como construir cidades mais resilientes: um guia para gestores públicos locais. Genebra: NU, nov. 2021. Disponível em:

https://www.unisdr.org/files/26462_guiagestorespublicosweb.pdf. Acesso em: 18 ago. 2021. 
RODRIGUEZ-DOMENECH, Maria A. R. Introducción. In: CLAUDINO, Sergio; RODRIGUEZDOMENECH, Maria A. R. Nosotros proponemos! Ciudadania, sostenibilidad e innovación geográfica ante los desafíos educativos de la sociedad. Barcelona: Graó, 2018.

SANTOS, Milton. Espaço e método. São Paulo: Nobel, 1985.

SANTOS, Milton. Metamorfoses do espaço habitado. São Paulo: Hucitec, 1988.

SANTOS, Milton. Por uma outra globalização. Rio de Janeiro: Record, 2000.

SANTOS, Milton. Técnica, espaço, tempo: globalização e meio técnico-científicoinformacional. São Paulo: Edusp, 2013.

SASSEN, S. The global city: New York, London, Tokyo. Princeton: Princeton University Press, 1991.

SCOTT. Allen J. Global city-regions: trends, theory, policy. Oxford: Oxford University Press, 2001.

SECRETARIA DE CIÊNCIA, TECNOLOGIA E INOVAÇÃO DO GOVERNO DO DISTRITO FEDERAL (SECTI). Entenda o que é uma smart city. 7 mai. 2019. Disponível em: http://www.secti.df.gov.br/entenda-o-que-e-uma-smart-city. Acesso em: 18 ago. 2021.

SERPA, Ângelo. O espaço público na cidade contemporânea. São Paulo: Contexto, 2007.

STORPER, M. The regional world: territorial development in a Global Economy. New York: Guilford Press, 1997.

TASCHETO, Marcio; MARCON, T.; MELLA, L. L. Tensões entre as pedagogias sócioemancipadora e tradicional: um estudo do sistema socioeducativo com adolescentes privados de liberdade. ECCOS Revista Científica, São Paulo, v. 48, p. 95-114-114, 2019. DOI: https://doi.org/10.5585/eccos.n48.11538

TOSTA, O. Teorias geopolíticas. Rio de Janeiro: Biblioteca do Exército, 1984.

TRINDADE JÚNIOR, Saint-Clair. A cidade dispersa: os novos espaços de assentamentos em Belém e a reestruturação metropolitana. 1998. Tese (Doutorado em Geografia) Universidade de São Paulo, São Paulo, 1998.

UNITED NATIONS. World Urbanization Prospects: The 2014 Revision. Department of Economic and Social Affairs, Population Division. New York: UN, 2015. Disponível em: https://population.un.org/wup/Publications/Files/WUP2014-Report.pdf. Acesso em: 18 ago. 2021.

UNITED NATIONS. World Urbanization Prospects 2018. Department of Economic and Social Affairs/Population Division. Country profiles. 2018. Disponível em: https://population.un.org/wup/Country-Profiles/. Acesso em: 18 ago. 2021. 
WEISS, Marcos C.; BERNARDES, Roberto C.; CONSONI, Flavia L. Cidades Inteligentes como nova prática para o gerenciamento dos serviços e infraestrutura urbanos: a experiência da cidade de Porto Alegre. Urbe - Revista Brasileira de Gestão Urbana, Curitiba, v. 7, n. 3, p. 310-324, dez. 2015. DOI https://doi.org/10.1590/2175-3369.007.003.AO01

Recebido em: 09/06/2021 Parecer em: 05/07/2021 Aprovado em: $27 / 07 / 2021$ 